\title{
Refractory Marginal Zone Lymphoma
}

National Cancer Institute

\section{Source}

National Cancer Institute. Refractory Marginal Zone Lymphoma. NCI Thesaurus. Code C143085.

Marginal zone lymphoma which does not respond to treatment. 